\title{
Darwinism in the Gym
}

\author{
Clive C. Pope \\ The University of Waikato
}

\author{
Mary O'Sullivan \\ The Ohio State University
}

This study examined the ecology of "free gym" as it occurred in both school lunch hour and after-school community settings. In an effort to understand how urban youth experience sport, an ethnography using multiple methods was conducted to ascertain how urban youth shape their own cultures according to the social forces operating within the gymnasium. A period of sustained observation revealed a student-imposed hierarchy that was dominated by skilled male African American basketball players. Status was gained through what occurred within the free-gym ecology. Students often had to learn the system by "serving time" before they could join a desired level of the hierarchy. While a few students thrived in this environment, most merely survived or were marginalized. Such a setting has implications for how physical education and school culture is subjected to wider societal influences. The presence of socially chronic situations such as free gym require a pedagogy that is more democratic and more enriching, thereby moving from the real toward the ideal.

Key Words: extracurriculum, youth culture, gymnasium ecology

...the socio-cultural dynamics that shape our lives in a larger society must be considered and analyzed in the instructional activities within sport if a full, rich, and accurate picture of sport pedagogy is to emerge. (Schempp, 1998, on-line)

Over 25 years have passed since Larry Locke shared his views of how important it is to reveal what goes on in the gymnasium and expose what the tourists never see. He argued for the need to examine the ecology of the gymnasium in order to understand teaching and learning (Locke, 1974). Life in the gym, according to Locke, was marked by complexity, diversity, time constraints, and the special nature of the subject matter of physical education. In particular, visiting the gymnasium could shed light on the physical education teacher and physical education as a subject.

Locke (1974) warned that much of the action that occurs in the gym is often unrecognized. While regular visitors may become accustomed to the movement and the sounds, "as full time actors in the play of roles that revolves around the

Clive Pope is with the Dept. of Sport \& Leisure Studies, The University of Waikato, PO Box 3105, Hamilton, New Zealand; Mary O'Sullivan is with the College of Education, The Ohio State University, 149A Arps Hall, N. High St., Columbus, OH 43210. 
gym, they often sense only the consequences of events without really discovering the social machinery that causes things to happen as they do" (p. 4). To better understand the world of physical education and those who teach it, he called for prolonged attendance to learn about the microcosm of gymnasium life.

However, researchers are not the only visitors to the gymnasium. The longterm visitors are the students, also tourists, who form part of the ecology. Their needs and experiences are often shaped by how life is within the walls of the gym. Moreover, what is learned beyond those walls in the form of an urban "street literacy" can seem contradictory to what teachers may seek to promote in educational settings, which often requires cooperation from young people (Cahill, 2000; Katz, 1995).

The purpose of this study was to examine the sport experiences of youth at one urban high school in a large U.S. city during the "open gym" at lunchtime, and during recreation times after school at selected community recreation centers. We endeavored to interpret how those experiences contributed to their physical education or mis-education. The focus of this study was on the sport (formal and informal) experiences of high school youth and not merely high school sport. While the students who participated were based at one high school, their sport experiences went well beyond traditional sport contexts. In addition, the study attempted to ascertain the opportunities and constraints that influenced the sport experiences of these urban youth. For many students, their only experiences of sport occurred either in physical education as part of the formal curriculum, or in other programs offered in high school that fall under the heading of the extracurriculum.

\section{Theoretical Framework}

\section{The Extra Curriculum}

Broadly conceived, education includes teaching and learning, socialization and enculturation, and takes place in formal, informal, and nonformal situations (Hansen, 1979). Like the functional curriculum, extracurricular activities can be touched by wider societal problems, and research reviews have pointed out that extracurricular participation contributes in vital ways to adolescent development (Berk, 1992).

Eder and Parker (1987) highlight the potential impact that schools can have on adolescents' values and behavior through extracurricular activity. They offer three reasons: First, unlike the structured nature of classroom contexts (Cusick, 1973), extracurricular activities hold the potential to become social events marked by interaction and meaningful participation. Second, the social dimension of extracurricular activities holds potential for interaction with the opposite sex. This issue has particular relevance in the U.S., where many physical education classes are sex-segregated. Third, student visibility is elevated amidst the peer group during many extracurricular activities. This enhanced status can in turn intensify membership in the peer culture.

Little is known about how young people consciously experience sport. Moreover, expressions of their needs have seldom been communicated directly to adults. The criteria young people adopt to evaluate their involvement in sporting experiences are often dependent on changing life situations (Brettschneider, 1990). Not enough attention has been allocated to this important component of the youth sport 
milieu, and therefore little is known about how youth receive, regard, define, and experience sport especially as it relates to informal sport.

A lack of opportunity to play is symptomatic of many U.S. school programs that usually support only one team per sport. While suburban youth may have a variety of sport opportunities, for inner city students the school may be their only opportunity for participation (Eitzen, 1995; Kozol, 1991). Their experiences are often hobbled by access and provision (Ewing, Seefeldt, \& Brown, 1996). The presence of a sport delivery structure that should cater to urban youth has resulted in an unfortunate paradox: "the general response to a growing concern about atrisk youth in the 1990s is to make school sport less accessible through the institution of pay-to-play plans" (Siedentop, 1996, p. 272). The result is a decline in youth sport among urban adolescents.

Decreased opportunities for many youth appear to have promoted two related trends. The first trend, fueled by their continued interest in sport, is the shift on the part of youth to more passive forms of sport participation. Because they are unable to be players, many, like their adult counterparts, subscribe to sport in the more passive role of spectator. The second trend, supported by increasing youth choices, has been a growing conflict of interest between academic pursuits, parttime work, and indulgence in at-risk behavior as alternatives to the demands of many sport programs.

\section{Revisiting the Gym}

To learn more about the educational value of high school sport, we need to examine youth and sport at a microanalytic level. Grupe and Kruger (1994) argue that there is a need to "be concerned with the discussion of values, ethics, and moral problems of sport and sport education" (p. 20). To enter into such discussion we need to examine the role of sport in the current value system of today's youth. Moreover, it is prudent to adopt an ecological framework (Bronfenbrenner, 1979, 1989) to examine what norms and values about sport are transmitted to today's youth by significant others.

High school students' participation in active leisure forms (such as sport) is determined largely by what they are interested in, which in turn is influenced by the availability of suitable resources (Garton \& Pratt, 1987, 1994). The issue at stake is the degree to which such responses are suitable for urban youth. Furthermore, the dominance of sport at the high school level is seen by the sustained salience of sport within the value structure of many urban youth. Young people gain acceptance by excelling in something that is valued by their peers (Evans \& Roberts, 1987).

The cloistering of students in a social cauldron like the gymnasium has promoted the peer culture (Brown \& Theobald, 1998). Such a culture can affect the relationships that are formed and the activities that are selected in a given context. As relationships form, individuals associate with like individuals and establish groups or crowds. The selection process may not always be at the discretion of the individual; rather his or her affiliation may be determined through group or crowd selection.

The goal of this study was to examine what occurs in urban school and community gymnasia during the time known as "free gym." A secondary goal was to examine the social interactions in those spaces and the implications for physical education, and for those who are taught. 
Berk (1992) reports that a "comprehensive review of the empirical literature ... yielded few ethnographic accounts... aimed at discerning the quality of students' experiences ... in extracurricular activities" (p. 1036). Berk argued that this was due to a "preoccupation of educational researchers with the quality of the American formal academic program" (p. 1035). To understand more about the ecology of physical education contexts, we must examine the nature and impact of other contexts because, as Brown and Theobald state,

Unresolved issues still fester, however, particularly concerning the major objectives that should underlie an extracurricular program, the nature and degree of connection that should exist between extracurricular participation and classroom learning, and the degree to which schools should take ownership of these activities. (1998, pp. 116-117)

This study involved revisiting the gymnasium and learning more about the social machinery that has an impact on youths' access to sport and the nature of urban youths' sport experiences.

\section{Methods}

Shady Woods is an urban high school in a large American city. It had an enrollment of over 800 students, of whom $66 \%$ were on a free or subsidized-lunch scheme. In all, $65 \%$ of Shady Woods students were identified as African American, $25 \%$ as Caucasian, $3 \%$ as Asian American, while the remainder included Hispanic, Native American, or "other" ethnic groups. Boys slightly outnumbered girls ( 51 vs. 49\%). Observation was the research tool by which we could gain an understanding of the setting. It allowed us to note the events and behaviors of the major players. Ethnographic research can rely on varying degrees of participant observation. The practice of observation was largely conducted using the more passive or peripheral forms of complete observer or participant as observer. It was considered beneficial to switch between these two derivatives to gain a sound understanding of local ecology without disrupting the existing social machinery at each of the three sites. Multiple methods were used to gain a better understanding of the immediate social circle and the wider cultural environments of these urban youth. The aim of participant observation was "a commitment to adopt the perspective of those studied by sharing in their day-to-day experiences" (Denzin, 1989, p. 156).

The works of Spradley (1980) and Werner and Schoepfle (1987) assert that observation can pass through a three-phase process of "descriptive observation" which leads to "focused observation." After attending to what is considered more important, observation may then proceed to the final phase of "selective attention" whereupon specific features of chosen activities are studied. Observation was selected to gain an appreciation of free gym because "ethnography appears a particularly well suited endeavor for the sport pedagogy scholar in search of the forces of social change that reside within the teaching/learning process of sport" (Schempp, 1998, on-line).

\section{Lunch-Hour Observation}

We visited free-gym sessions at the Shady Woods High School gymnasium over a period of 5 months. During each visit we maintained a position on the top row of the bleachers or at the edge of the basketball court. The former strategy was 
to gain a bird's eye view of the dynamics and behavior of whoever was on the floor; the latter strategy focused on particular groups or on the interactions between students. The free-time sessions occurred between 10:30 and 11:30 every morning. A teacher (usually a physical educator) allocated five of six basketballs and then positioned him/herself at the doorway of the gym. Student attendance varied depending on who was playing, the weather, or events elsewhere in the building that day. On average, between 80 and 130 students occupied the gym. The numbers would fluctuate during the hour and would usually increase toward the end of lunchtime. Occasionally one of us would talk with a student or a staff member who was present, but generally our role was purely that of observer.

\section{Community Observation}

From early conversations with Shady Woods students, two recreation centers were identified as sites where students would "hang" after school. One center, Northside, was three blocks from Shady Woods while the other, Crosstown, was situated several miles across the city. "Northside Recreation Center" was visited four times while "Crosstown Recreation Center" was visited twice. Trips to these two venues were mostly straight after school or in the evenings and each visit would last 90 to 120 minutes. The number of Shady Woods students in attendance at these two centers fluctuated between 15 and 40 .

\section{Fieldnotes}

At each of the three venues fieldnotes were taken. This would involve either talking into a microcassette recorder or writing in a small notebook, depending on the context. If the observer's presence was unobtrusive, a cassette recorder was used because it produced a better record when there was a lot going on. If the observer was close to other people or if it was not possible to use a cassette to record observations, these were entered into a notebook at the earliest convenience. The observer also made comments into the tape recorder upon returning to the car or while driving between venues.

Observation entailed constant scanning from the periphery of a venue and "observing out loud" (Allison, 1988). It was a matter of focusing on quite general things at first before familiarity allowed a more concentrated attention. Initial observation would ask: Who was there? What age and gender were they? What were they wearing? Who were they interacting with? What were they doing? How long did they do it for? How were they arranged? When possible, the observer would revisit sites with new and more focused questions. However, students who visited the venues varied significantly each day and this often restricted how questions could be answered.

The final component of the observation process involved making entries into a $\log$ on a home computer. This log became a repository for ideas, events, hunches, and issues. Each page of the log was divided into three columns: observational notes, personal notes, and theoretical notes. Entries made in the log would be reread regularly before returning to the observation sites.

We both adopted strategies to address trustworthiness during the data collection and analysis process. First, a peer debriefing strategy ensured that it would be the respondents' rather than the researchers' categories that would dominate the findings (Lincoln \& Guba, 1985). This included regular meetings during which 
findings and interpretations were audited to establish a consensual validation. Moreover, we reworked the assertions until we felt we were representing the students' thoughts and actions and not imposing our own viewpoint. The final strategy involved prolonged involvement with those being studied, gathering from multiple data sources (interviews and observations) of the students in the environment.

The analysis assumed a two-tiered approach: a descriptive review of the contextual characteristics that influenced free gym; and an interpretation of the data that supported the task of asking why specific results had emerged through observation. Each characteristic was examined inductively to establish lower level descriptors that contributed to higher level categories (Patton, 2001). This process was constantly adopted to confirm, modify, disregard, or merge raw data into dominant themes and categories.

\section{Results and Discussion}

A major finding was that a student-imposed hierarchy determined the nature and degree of participation each student could assume during free-gym play. Any attempt by students to elevate their status within the free-gym ecology required that they do their time by serving an apprenticeship at a subservient level. In addition, a degree of movement literacy was expected of practicing and potential players as well as observers. To survive or thrive in this ecology, a participant has to possess a certain degree of street literacy involving both physical ability and "street smarts."

If the meanings that many youth develop about sport are based on personal experience, then what occurs during free-gym sessions at the school and community facilities may discourage participation among a large number of youth. Informal and unstructured games, minimal or no adult presence, and casual groups of spectators who seldom stayed for long periods of time marked the two field settings. Virtually every site was marked by pick-up basketball games, a strong social ambiance, and a clear but implicit set of rules for behavior. It was a place to hang out with friends and to check who was playing or waiting to play.

\section{Lunch-Hour Free Gym: A Cultural Caldron}

The Shady Woods gym is a double size basketball court and, with the bleachers retracted, allows students to utilize all six basketball rings. There was usually one basketball available for each basket, and the lunchtime bell signaled a race to get one of the balls and ensure a chance to play at one of the baskets. This venue was a place to gather, to greet friends, to hang out, and to compete. Every morning between 10:30 and 11:30 the gym was open to all students. A staff member, usually a physical education teacher, was stationed at the only door through which students could enter or exit. During this hour the gym was frequented by large numbers of students.

The only activity pursued was basketball, or what the young people referred to as "ballin." The activity was spontaneous, unstable, intense, and very public. Once a student found a ball, he or she would congregate with peers and organize a pick-up game. It was usually a small-team game such as 3 v 3 or 4 v 4 . Each 
contest was characterized by long periods of verbal jousting or "trashing" while some player walked around and around the periphery of the half court area, waiting for an opportune time to begin play. The other version of "ballin" was taking turns at shooting from self-selected sites, with the shooter keeping the ball if he was successful. The shooting version was very unstable as the activity could break up at any time or the number of participants could change rapidly.

On most days there were over 40 students on the floor 5 minutes after the bell rang to begin the lunch period. As the lunch hour continued, the numbers swelled, depending on the day of the week and what else was happening in the school. On the floor $90 \%$ of the participants were boys and mostly African American. When girls played, they always played at the basket nearest the door; this was the least favored venue as students walking in and out of the gym often interrupted games at that basket. On several days that same basket would be taken over by boys, or by some girls who stood their ground or who compromised and allowed a mixed-gender game.

The geography of this venue altered according to who was present. A power structure was obvious. Certain students determined who played at what baskets and how much space they had to play their game. If certain male athletes decided they wanted to play, they would often take one of the two small courts to play a game in front of a reasonable size crowd. Occasionally they would set up a game on the main court, forcing other players off the floor or confining them to a very small area under the four side baskets. These players were often juniors or seniors on the school basketball team. If they began a game, it would attract several spectators. On occasion some students refused to give up their game space on the side baskets and endured players running through their area.

The young people who frequented the gymnasium fell into loosely defined groups somewhat akin to the categories of students Griffin $(1984,1985)$ observed in the middle school physical activity setting. Altogether there were 7 groups:

1. Bullies. Bullies were always male, usually senior, and often skilled performers. They often dictated what game could be played and where. Their games usually resembled an exhibition in slam-dunking with virtually no midcourt action. The more spectators present, the more intensely the Bullies performed. As the intensity of their games increased, they would spend more and more time dribbling the ball at the top of the "key" and just verbally trash (ridicule or abuse) each other, exchanging jibes for several minutes before beginning a new play for the basket. Their most intense performances were on days when the basketball team members were not involved in interscholastic competition. If a Bully was not playing, he often positioned himself alongside other peers (some of whom were Bullies) beside another game and trashed the players on court. This behavior was particularly popular as Bullies often fed off each other as they trashed their selective targets:

A tall, lean African American male calls from the sideline, "You want some of this?" One of the players replies, "We'll take the money," at which point he launches a pass like a bullet to a teammate who shoots only to have it rejected by an opponent... The sideline observer replies "sad," which draws an icy stare from the unsuccessful shooter who has retrieved the ball and duly heaves it toward the roof, narrowly missing a suspended light. (Fieldnotes) 
2. Jousters. Jousters consisted of a small group of boys intent on disrupting as many games as they wished to risk. They would often steal a basketball and run to another basket with it. They often did this to girls who might be playing a game. In addition, Jousters would intrude during a game and often try to slap the ball out of a player's hands:

The Court 4 game is interrupted by an invader who tries to slap the ball from its possessor unsuccessfully. Having failed to gain possession of the ball, the intruder then attempts to foot-trip his elusive target. Again, he is unsuccessful and proceeds to move onto Court 3. (Fieldnotes)

His action is unnoticed by the duty staff member who is positioned a significant distance away.

Another behavior was to stand right under the basket in the middle of a game, thereby forcing some form of confrontation or retaliation. Some Jousters enjoyed selecting a player and just punching him a few times or kicking at him to get a response. Some would use these tactics to get into a game and, if they didn't succeed, they would move around the baskets like nomadic disturbances. This self-selection process was quite contrary to the subtle negotiation that took place between other participants. Invariably Jousters were not skilled basketball players and would not have been picked for games.

3. Posers. Posers were some 10 boys who seldom participated but used this forum to show peers their physique and what they could do. A favorite activity of several Posers who worked out in the weight room was to strip to the waist and walk around the gym with their top draped around the waist. Their upper body would often be adorned with gold chains. Some of this group would perform pullups on the basketball ring during games. Other behaviors included punching the mats on the walls vigorously several times or kicking any ball that strayed in their direction. Occasionally a Poser would try to get the attention of people on the floor. It was not uncommon for a Poser to put on a pair of red sweat pants, roll up one leg, and walk around the floor. Demonstrations of this nature were generally ignored by other free-gym participants and the teacher supervisors.

4. Benchies. Benchies included some girls but were usually boys. On most days there were 30 to 40 students in this group. They would hope to play but often spent the entire lunch hour just waiting for a chance to play. They usually congregated directly under the basket to make sure the players were aware of their intentions. Benchies would wait to be invited on court, or they drifted onto the court when pick-up games were starting and hope to be included in the numbers.

A junior student leans against the wall behind the basket of Court 5. He wears a Nuggets 55 top and has long silky shorts that hang to his kneecaps. He constantly monitors the periphery of the court sizing up other wannabe players. As a game breaks up, he is one of several students to meander onto the floor and assemble under the basket while a few shots are thrown up. With one eye cast toward the basket, he is also constantly panning the court to catch the attention or eye contact of his peers. Some of the players have collected in small groups that appear to be the next game teams. His presence is not required and, once again, he resumes his position leaning on the wall to continue his vigilant role. (Fieldnotes) 
Benchies would sometimes have friends or classmates who were on court; they usually arrived early and changed into their basketball hightops or stood holding them in case they might be called onto the court.

5. Hangers. Hangers were evenly made up of boys and girls who would turn up in the gym just to see what was going on and who was there. They often congregated by the doors with the supervising teacher, drifting in and out during lunch hour. They would bring food or drink into the gym and share with friends during their conversations. This gesture was in direct violation of school rules but there seemed to be a total disregard for such a violation. Hangers usually frequented the gym if there was not much happening elsewhere in the school. If a good game was occurring, they would somehow get the message and enter en masse. A confrontation between players would also ensure the arrival of the hangers to the scene. Some group members merely used the gym as a place to chat or read a book in the company of others.

6. Venerators. Venerators were almost all well-dressed girls, often in the 9 th or 10th grade. For this group the gym was a place to check out other people as well as be seen by significant others, particularly male athletes. Venerators made their presence felt by walking up and down the sideline or selecting a performer and trying to catch his attention. The more confident Venerators would often try to start a conversation with a player, and if that failed, they would begin baiting him with jibes or quips.

Josh, a member of the varsity team, receives the attention of three admirers. A successful 3-point shot draws the response, "You good," which Josh tries to ignore but is unable to conceal a smirk on his face. His three admirers giggle and push each other, causing Jenny, who is dressed in high heels, to stumble and look very embarrassed. Jenny asks, "You teach me how to do that?" to which Josh retains his grin but no further response occurs. He walks away from them and his departure earns a response, "Be cool," from Jenny, who has now regained her balance and her composure. She pretends to ignore him and convinces her two friends that they are wasting their time. (Fieldnotes)

The girls worked in groups of two to four. If the selected target did not acknowledge their attention, they would often get louder and more conspicuous in their behavior until they got his attention.

7. Contestants. Contestants were those who played basketball. With the exception of three or four girls, this group was all male and mostly African American. They ignored almost all around them and became engrossed in their pick-up games. These participants were skillful players. They took their competition seriously and played with intensity. Contestants played by agreed-upon rules and usually remained on court until the bell rang. They were often quite vocal both on and off the court. Most of them were confident and extremely competitive. Although they usually played in $4 \mathrm{v} 4$ games, they often indulged in $1 \mathrm{v} 1$ plays within the game. Their goal each lunch hour was to play a good close, competitive game.

Virtually anyone who entered the gym at lunchtime could be linked to one of these groups. For many of the students, playing in this forum was very public and quite risky. It was, however, an acknowledged proving ground for players who 
entered. Any aspiring basketball players had to prove themselves within a selected group before they would be accepted at a higher level.

Two underlying messages evolved from this venue: First, this was a male domain and the boys adopted several tactics to make sure people were where they wanted them to be. Second, if you wanted to be noticed by your peers, whether it be how you looked, what you were wearing or, more important, what you could do on the court, this was the place to do it.

\section{A Similar Community Picture}

Free-gym period at Shady Woods was similar to what occurred at the local recreation center. The after-school program started shortly after 2:30 p.m. By 2:45 the gym began to fill; it had two courts and six baskets. There were six basketballs available and the new arrivals raced to claim a ball. The following fieldnotes illustrate some of those similarities:

I am recognized by several of the youth who arrive at the center. "What you doin here?" they ask. The majority are dressed in shorts, T-shirt, and hightops. The center appears to be a place to "hang" as several of the kids congregate on the only row of the bleachers that is not retracted. On the second court the coordinator joins in on a game with seven older boys. He controls the game, coaching the players as well as playing himself. The seven girls in the gym have all retired to the bleachers. The kids on the bleachers converse among themselves about who did what or who should have done something else. The "big" game is very physical and played at a fast pace. The gallery increases in size and a new arrival calls, "Who's got next?" as he surveys who is in the gallery.

My note-taking catches the attention of a young woman who asks, "Are you NBA?" I smile at her and ask if she is going to play, to which she responds, "No they don't let girls play... they sexist!" whereupon she takes another swig of her Mountain Dew. The player who was marked by the coordinator voices his concerns that he has been pushed around by his opponent who is taller and considerably bigger than him. The young player's protests are met with, "You cryin all the time... you cry baby... Hey, we beat you by two... we beat you by two." The losers retire to the foyer to get a drink. (Fieldnotes)

The picture was similar across town at a center that also has Shady Woods students in attendance. Those attending were nearly all African American. The open-roll policy of the school meant that students could attend Shady Woods from throughout the city. The following fieldnote illustrates a similar ecology across town:

They organize pick-up games between themselves while the supervisor sits at the doorway and monitors behavior. She warns them, "The next cuss word means you are all out of here." Her warning is heeded. The center remains open until 10 p.m. Games dissolve into shooting contests or are transformed into another game almost without warning. Unlike their observer, the players seem to know how the system works. The young people advise me that they usually only play basketball and participate in the sport for most of the year. "Basketball is cool." (Fieldnotes) 
Numerous visits to venues confirmed that the highly competitive nature of the games seemed to attract boys to organized and recreational sport more than girls. The intensity, physicality, and degree of "trashing" that occurred in many games we observed confirmed that the players often treated their games as though there was a lot at stake. This was evidenced at both recreation centers as well as at Shady Woods during lunch hour. Amanda, who has tried to understand why the boys take basketball so seriously, related her conversations with boys who play ball during lunchtime free gym:

They tell you, like, if they didn't do good or beat anybody, then they're not good enough for themselves so they get mad with themselves. And they sometimes try blaming it on other people when it's really their fault. I mean, they just have to accept that they can't and they have to do better.

The intensity that sometimes evolved from sporting encounters was not restricted to the boys. Jenna, who was one of the few Shady Woods girls to play ball during lunch hour, signaled a concern that,

There's a lot of people who take the games too serious and them's the ones you got to watch out for because they're the ones that will want to start a fight with you, want to pick a fight... but that's basically it.

It is possible that such demonstrations serve as "cool pose" (Patterson, 1997) resistance to or dissatisfaction with parts of the existing sport system in high school.

Preference for basketball was illustrated during daily open-use gym sessions during lunch hour. It was the only sport ever played in the gym during the 5 months of observation at the school. This engagement with basketball, particularly by African American males, has been described as a "selective overemphasis of a dominant cultural norm" (Patterson, 1997, p. 188). Patterson drew on personal research of African American youth and discovered that "getting a young girl pregnant and being good at sports, or just being sports obsessed, are together the coolest things one can do and be" (p. 188). Basketball is cool at Shady Woods. However, it was available only to the few self-selected "cool-pose" participants who had the skills and confidence to control the situation. As Traci, a senior nonparticipant, said, "Nobody is going to say anything. They have their way and it's the same thing over and over again. Every day it's basketball, basketball."

The lunchtime power structure was dominated by skilled male African American basketball players. There was a clear expectation that everybody would conform to the norms of behavior established by this group. Most students were reluctant to challenge the power structure. We believe this situation is not unique to Shady Woods High School lunchtime or to midwestern or urban schools.

During free-gym periods the basketball games were intense, competitive, and public. Anybody who wanted to play had to be good enough to get a place on a pick-up team and deal with attention from students who were watching. Many players were subjected to taunts and jeers from their peers. The power structure that evolved in the gym at Shady Woods privileged skilled, mostly African American male athletes while girls and less skilled boys were often excluded. While the issue of gender exclusion has been the focus of research in physical education environments (Bain, 1990; Carlson, 1995; Kollen, 1981), attention to informal sport settings has been meager. Even girls like Jenna, a competent basketball player, 
were reluctant to actively participate in free gym. If an environment is perceived as too public and marked by intense peer scrutiny, the perceived risks may outweigh the benefits of participation. By contrast, those who stayed were the skilled, boisterous, and aggressive. For them, success was virtually assured, as they had the necessary traits to survive. They were the advantaged and others had to adapt or retreat. The gym supported a differential survival whereby those who had power survived. It is a very negative example of a Darwinian existence.

In an educational setting, the characteristics of a Darwinian climate based on survival of the fittest are inappropriate. While we have conducted this study in light of the basic characteristics of Darwinism, we do not wish to enter into a theoretical discussion on Darwinian doctrine. We would, however, point to the need for an educationally sound alternative for how urban youth could evolve in a sport setting. For example, Depew (1996) suggested:

Perhaps it is not too much to say that what we need is an evolutionary theory worthy of our best social theory, not a theory trimmed to fit a rapidly receding, overly simplistic, evolutionary theory. For our part, we look forward to an ecologically grounded evolutionary theory whose point is the protection of individuals, communities, and their traditions in a natural world that is our true and only home. (p. 495)

However, it was evident that sport was very much a part of this youth culture and that it had an established power structure. Status could be gained through sport participation and approval from significant others. Observation of the free-gym situations indicated that the power players were the Bullies. They determined the space allocation, they attracted the biggest crowds, and they were the group that other participants aspired to become. As a Bully, you were expected to be an extremely competent player and learn the local culture, its conventions and its characteristics, in essence almost like an apprenticeship.

\section{Learning by Apprenticeship}

In a study that explored elements of successful programs, Resnick (1987) found that the notion of apprenticeship as a means of learning "allows skill to build up bit by bit, yet permit participation even for the relatively unskilled, often as a result of social sharing of tasks" (p. 18). Lave and Wenger (1991) suggest that "learners inevitably participate in communities of practitioners and that the mastery of knowledge and skill requires newcomers to move toward full participation in the socio-cultural practices of the community" (p. 29).

Before full participation can occur, apprenticeship is often served, requiring the novice learner to indulge in a limited form of legitimate peripheral participation. As he or she serves his/her apprenticeship, “a person's intentions to learn are engaged and the meaning is configured through the process of becoming a full participant in the socio-cultural practice. This social process includes, indeed it subsumes, the learning of knowledgeable skills" (Lave \& Wenger, 1991, p. 29). This model of learning holds true for the ecology of the free-gym environment. Many students had to "do their time" on the periphery of the court before they could gain access to games of increasing complexity and status. But it was not only the game and its associated skills that had to be learned. Ambitious and hopeful players had to learn and accept the social conventions associated with each 
game of basketball. In many cases, to learn the game's social conventions was more important than the performance itself. Such a process promotes one's survival as a future participant. These attitudes and behaviors are a reflection of street literacy and leave no room for less able and less aggressive students to participate in a positive physical activity experience.

\section{Street Literacy and the Ways of Youth}

The production of informal knowledge from practices that occur within contexts such as free gym has been referred to as street literacy. Cahill (2000) suggests that "street literacy is an interpretive framework that privileges experienced informal local knowledges that are grounded in personal experiences and passed down in the form of rules, boundaries set by parents, neighborhood folklore, and kids' collective wisdom" (p. 252). She argues that urban learning sites such as pick-up basketball venues hold considerable significance for young people who attend such contexts. It is within such specific contexts that urban youth can construct knowledge based on personal and social experiences.

This perspective is supported by Resnick (1987), who argues that "work, personal life, and recreation take place within social systems, and each person's ability to function successfully depends on what others do and how several individuals' mental and physical performances mesh" (p. 13). Moreover, each individual must compete not only with the performances of others but also "with larger institutional, social, and economic contexts" (Cahill, 2000, p. 271). Urban youth are therefore the holders of multiple worlds that intermesh and compete, thereby influencing how each young person expresses himself/herself.

While free gym can be a forum in which many urban youth have the opportunity for self-expression, the dynamics at Shady Woods would indicate that for most students the opportunities are nonexistent. The social machinery evident at Shady Woods reflects Larry Locke's observation that "It is easy to believe, however, that student influence is both great and sometimes destructive to educational purposes" (1974, p. 15). According to Katz (1995), it would appear that the ecology of free gym is marked by power, space, and terror.

Katz (1995) reports that while many outdoor environments suffer from "benign neglect," young people are increasingly seeking the safety of indoor spaces. Moreover, what play that remains in outdoor leisure environments is repeatedly taken over by boys, with girls often being restricted from such unsupervised spaces. The school thus becomes one of the few preserves for youth seeking active leisure. Sadly, our research would suggest that while the venue may have changed, the educational setting itself has fallen victim to benign neglect. Our prolonged presence at Shady Woods suggested that the Darwinian existence of free gym received the tacit approval of staff. Those who supervised the lunch-hour sessions indicated that it served as a cathartic outlet for students and that it was not advisable for them as supervisors to rock the boat.

The question one must ask is, "What are we, as physical educators, going to do about it?" Clearly the nature of free gym has implications for physical education. It is perhaps indicative of the challenge that physical education teachers must face between school culture and that of the wider society. At a micropolitical level, any attempt by teachers to change classroom culture will first require attention to and knowledge of those wider cultural influences (such as street literacy) as significant determinants of what occurs in the gym during physical education. 
The changing contexts of the youth sport culture have implications for how sport can and should be delivered or, more important, how it has been delivered. If youth are to be given options for participation, those options must be viewed as viable, attractive, appropriate, and enjoyable. Tinning and Fitzclarence (1992) have argued that for postmodern youth culture, "the disjunction between physical education and the place of physical activity in their out-of-school lives is contradictory" (p. 301). This perspective is endorsed by Csikszentmihalyi (1993), who argued that "we bring up children to take their places in a culture that, in reality, no longer exists. The basic skills they learn have little to do with survival in the future" (p. 276). While free gym occurred during lunch hour, the realities of such a setting appeared to have an impact on the ecology of physical education classes (see O'Sullivan, Tannehill, Knop, Pope, \& Henninger, 1999; Pope \& O'Sullivan, 1998).

Students who were marginalized by the free-gym ecology reported for physical education classes at the same venue and often alongside the same students who either controlled or benefited from how life was ordered during lunch hour. The implication suggests that many students would be required to learn and embrace a different ecology for physical education, while at the same time living with the powerful and pervasive student-centered alternative during noninstructional school time.

If we as educators remove ourselves from ecologies such as free gym, only a few young people will be allowed to survive and learn what appear to be desirable skills in a culture of convenience for a small but powerful group. Teachers and students may need to find some middle ground between these ecologies. Brown and Theobald (1998) argued, "the aim of these [extracurricular] activities, therefore, should be to meet all students' needs, to enrich their learning experiences, rather than to create a small cadre of exceptionally skilled youth" (p. 133). As teachers, we have a moral responsibility to arrest socially chronic situations such as free gym. While such a context is "free" of teacher authority, it cannot really be termed free unless all restraint, including that which is placed by dominant peers upon their less dominant peers, is removed.

Today's youth value social affiliation, and a context like free gym has the potential to promote something that is inextricably attractive to them. To realize that potential, a compatible pedagogy must be employed. This would not mean building from scratch. Social development (Hellison, 1995; Hellison, Cutforth, Kallusky, et al., 2000) and sport education (Siedentop, 1994) models have already emerged as viable options to promote sport as an inclusive physical education and sport environment.

Traditional ethnography has often explored the difference between ideal and real culture (Angrosino \& Mays de Perez, 2000). The ecology at Shady Woods illustrates the "real" which, as educators, we could compare to our perception of the ideal sporting environment that is educational and marked by enjoyment, learning, and access for all who seek it. The ideal/real contrast is something that many teachers and teacher educators are faced with. It required us to position ourselves as white middle class educators anchored in an environment dominated by urban male African American youth. We cannot assume an ideal, nor can we assume a universal meaning because meaning shifts from one ecology to another.

Although this study reflects the ecology of one extracurricular context, some of the issues raised are similar to those experienced elsewhere. In England, Penney and Harris (1997) argue, there is a need to reevaluate the provision and content of 
extracurricular activity. Similarly, James (1999) has highlighted the dominance of skilled Australian boys in casual basketball settings who exclude and dissuade others, particularly girls, from participating in the activity. While we may not have the immediate answers, it is important, as Willard-Holt (2000) has contended, to pay credence to the lived experiences of young urbanites to thereby provide a meaningful education for them.

\section{Conclusion}

To ameliorate the delivery of sport in urban high schools, teachers need to acknowledge the impact of street literacy. In so doing, they may have some hope of moving from the real toward the ideal. Ethnographies can reveal a great deal about the ecology of the gym, but do we merely report ethnographies that give readers a perspective of how it is? Or do we take it one step further and seek to create social or educational change because the universal rights of some participants (girls and less skilled boys) are marginalized?

Sport is arguably a pervasive characteristic of everyday urban life. More important, it forms a significant part of school life. The question we must ask is, If sport is situated within a school context, is it educational? Gerdy (2000) has warned us that "sport is becoming so disconnected from educational values and foundations that it is in grave danger of becoming educationally irrelevant" (p. xi). Although free gym thrives in many urban schools, it is rarely part of the wider educational debate. It is evident from this study that many of the potential qualities that sport could offer as an educational medium have either been diminished or lost.

David Hamburg of The Carnegie Council on Adolescent Development stresses that for adolescents to make the transition to adulthood, they will require "an array of stimulating, constructive opportunities throughout their waking hoursboth in school and beyond" (1997, p. 11). Accordingly, there needs to be a place where interesting programs are available to those who seek health and enjoyment through sport. The challenge for teachers is to ascertain whether the suitability of participant experiences in certain sport forms is meeting the developmental and social needs of many young people. Any effort to enhance the wider sport culture should include paying credence to the experiences young people have with sport.

\section{References}

Allison, P.C. (1988). Strategies for observing during field experiences. Journal of Physical Education, Recreation and Dance, 59(2), 28-31.

Angrosino, M.V., \& Mays de Perez, K.A. (2000). Rethinking observation. In N.K. Denzin \& Y.S. Lincoln. (Eds), Handbook of qualitative research (2nd ed., pp. 673-702). Thousand Oaks, CA: Sage.

Bain, L. (1990). A critical analysis of the hidden curriculum. In D. Kirk \& R. Tinning (Eds.), Physical education, curriculum and culture (pp. 23-42). London: Falmer Press.

Berk, L.E. (1992). The extracurriculum. In P.W. Jackson (Ed.), Handbook of research on curriculum (pp. 1002-1043). New York: Macmillan.

Brettschneider, W.D. (1990). Adolescents, leisure, sport and lifestyle. In T. Williams, L. Almond, \& A. Sparkes (Eds.), Sport and physical activity: Moving towards excellence (pp. 536-550). London: E \& FN Spon.

Bronfenbrenner, U. (1979). The ecology of human development: Experiments by nature and design. Cambridge, MA: Harvard University Press. 
Bronfenbrenner, U. (1989). Ecological systems theory. Annals of Child Development, 6, 187-249.

Brown, B.B., \& Theobold, W. (1998). Learning contexts beyond the classroom: Extracurricular activities, community organizations, and peer groups. In K. Borman \& B. Schneider (Eds.), The adolescent years: Social influences and educational challenges (pp. 109-141). Chicago: University of Chicago Press.

Cahill, C. (2000). Street literacy: Urban teenagers' strategies for negotiating their neighbourhood. Journal of Youth Studies, 3, 251-277.

Carlson, T. (1995). We hate gym: Student alienation from physical education. Journal of Teaching in Physical Education, 14, 467-477.

Csikszentmihalyi, M. (1993). The evolving self. New York: Harper Perennial.

Cusick, P.A. (1973). Inside high school: The student's world. New York: Holt, Rinehart \& Winston.

Denzin, N. (Ed.) (1989). The research act: A theoretical introduction to sociological methods. Englewood Cliffs, NJ: Prentice Hall.

Depew, D. (1996). Darwinism evolving: Systems dynamics and the genealogy of natural selection. Cambridge, MA: MIT Press.

Eder, D., \& Parker, S. (1987). The cultural production and reproduction of gender: The effect of extracurricular activities on peer-group culture. Sociology of Education, 60 , 200-213.

Eitzen, D.S. (1995). Classism in sport: The powerless bear the burden. Journal of Sport and Social Issues, 20, 95-105.

Evans, J., \& Roberts G.C. (1987). Physical competence and the development of children's peer relations. Quest, 39, 23-35.

Ewing, M.E., Seefeldt, V.D., \& Brown, T.P. (1996). Role of organized sport in the education and health of American children and youth. East Lansing, MI: Institute for the Study of Youth Sports, Michigan State University.

Garton, A.F., \& Pratt, C. (1987). Participation and interest in leisure activities by adolescent schoolchildren. Journal of Adolescence, 10, 341-351.

Garton, A.F., \& Pratt, C. (1994). Leisure activities of adolescent school students, predictors of participation and interest. Journal of Adolescence, 14, 305-321.

Gerdy, J.R. (Ed.) (2000). Sports in school: The future of an institution. New York: Teachers College Press.

Griffin, P.S. (1984). Girls' participation patterns in a middle school team sports unit. Journal of Teaching in Physical Education, 4, 30-38.

Griffin, P.S. (1985). Boys' participation patterns in a middle school team sports unit. Journal of Teaching in Physical Education, 4, 100-110.

Grupe, O., \& Kruger, M. (1994). Sport pedagogy: The anthropological approach. Sport Science Review, 3(1) 18-27.

Hamburg, D.A. (1997). Meeting the essential requirements for healthy adolescent development in a transforming world. In D.A. Takanishi \& R. Hamburg (Eds.), Preparing adolescents for the twenty-first century (pp. 1-12). Cambridge: Cambridge University Press.

Hansen, J.F. (1979). Sociocultural perspectives on human learning: An introduction to educational learning. Englewood Cliffs, NJ: Prentice Hall.

Hellison, D. (1995). Teaching responsibility through physical activity. Champaign, IL: Human Kinetics. 
Hellison, D., Cutforth, N., Kallusky, J., Martinek, T., Parker, M., \& Stiehl, J. (Eds.) (2000). Youth development and physical activity. Champaign, IL: Human Kinetics.

James, K. (1999). "I feel really embarrassed in front of the guys!" Adolescent girls and informal school basketball. The ACHPER Healthy Lifestyles Journal, 46(4), 11-16.

Katz, C. (1995). Power, space and terror: Social reproduction and the public environment. Presented at the Landscape Architecture, Social Ideology and the Politics of Place conference. Harvard University, Cambridge, MA. Unpublished paper.

Kollen, P. (1981). The experience of movement in physical education: A phenomenology. Unpublished doctoral dissertation, University of Michigan.

Kozol, J. (1991). Savage inequalities. New York: Crown Publishers.

Lave, J., \& Wenger E. (1991). Situated learning: Legitimate peripheral participation. Cambridge: Cambridge University Press.

Lincoln, Y., \& Guba, E. (1985). Naturalistic inquiry. Beverly Hills, CA: Sage.

Locke, L.F. (1974). The ecology of the gymnasium: What the tourists never see. SAPECW Workshop, Gatlinburg, TN. (Eric Document No. ED 104 823)

O’Sullivan, M., Tannehill, D., Knop, N., Pope, C., \& Henninger, M. (1999). A schooluniversity collaborative journey toward relevance and meaning in an urban high school physical education program. Quest, 51, 225-243.

Patterson, O. (1997). The ordeal of integration. Washington, DC: Civitas.

Patton, M.Q. (2001). Qualitative research and evaluation methods (3rd ed.). Thousand Oaks, CA: Sage.

Penney, D., \& Harris J. (1997). Extra-curricular physical education: More of the same for the more able? Sport Education and Society, 2, 41-54.

Pope, C., \& O'Sullivan, M. (1998). Culture, pedagogy and teacher change in an urban high school: How do you want your eggs done? Sport Education and Society, 3, 201-226.

Resnick, L.B. (1987). Learning in and out of school. Educational Researcher, 16(9), 13-20.

Schempp, P. (1998). The dynamics of human diversity in sport pedagogy scholarship. Sociology of Sport On-line [On-line. Retrieved July 30, 2001]. Available: http:// physed.otago.ac.nz/sosol/v1i1/v1i1a8.htm

Siedentop, D. (1994). Quality PE through positive sport experiences: Sport education. Champaign, IL: Human Kinetics.

Siedentop, D. (1996). Valuing the physically active life: Contemporary and future directions. Quest, 48, 266-274.

Spradley, J.P. (1980). Participant observation. New York: Holt, Rinehart \& Winston.

Tinning, R., \& Fitzclarence L. (1992). Postmodern youth culture and the crisis in Australian secondary school physical education. Quest, 44, 287-303.

Werner, O., \& Schoepfle, G.M. (1987). Systematic fieldwork: Vol. 1. Foundations of ethnography and interviewing. Newbury Park, CA: Sage.

Willard-Holt, C. (2000, March). Preparing teachers for urban settings: Changing teacher education by changing ourselves. The Qualitative Report, 4(3/4), Article 05. Retrieved March 31, 2001, from http://www.nova.edu/ssss/QR/QR4-1/willard.html 